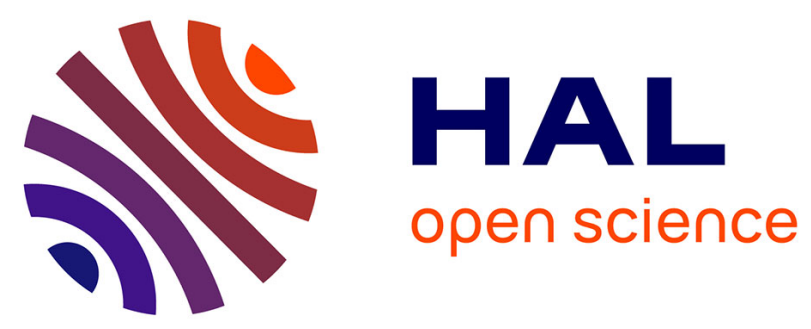

\title{
Lead-free piezoelectric crystals grown by the micro-pulling down technique in the BaTiO3-CaTiO3-BaZrO3 system
}

Philippe Veber, Karol Bartosiewicz, Jérôme Debray, Guillaume Alombert-Goget, Omar Benamara, Vincent Motto-Ros, Maï Pham Thi, Ana Borta-Boyon, Hugues Cabane, Kheirreddine Lebbou, et al.

\section{To cite this version:}

Philippe Veber, Karol Bartosiewicz, Jérôme Debray, Guillaume Alombert-Goget, Omar Benamara, et al.. Lead-free piezoelectric crystals grown by the micro-pulling down technique in the BaTiO3CaTiO3-BaZrO3 system. CrystEngComm, 2019, 21 (25), pp.3844-3853. 10.1039/c9ce00405j . hal02187642

\section{HAL Id: hal-02187642 \\ https://hal.science/hal-02187642}

Submitted on 2 Dec 2020

HAL is a multi-disciplinary open access archive for the deposit and dissemination of scientific research documents, whether they are published or not. The documents may come from teaching and research institutions in France or abroad, or from public or private research centers.
L'archive ouverte pluridisciplinaire HAL, est destinée au dépôt et à la diffusion de documents scientifiques de niveau recherche, publiés ou non, émanant des établissements d'enseignement et de recherche français ou étrangers, des laboratoires publics ou privés. 


\title{
Lead-free piezoelectric crystals grown by the micro-pulling technique in the $\mathrm{BaTiO}_{3}-\mathrm{CaTiO}_{3}-\mathrm{BaZrO}_{3}$ system
}

\author{
Philippe Veber ${ }^{1}$, Karol Bartosiewicz ${ }^{2}$, Jerome Debray ${ }^{3,4}$, Guillaume Alombert-Goget ${ }^{1}$, Omar \\ Benamara ${ }^{1}$, Vincent Motto-Ros ${ }^{1}$, Mai Pham Thi ${ }^{5}$, Ana Borta-Boyon ${ }^{5}$, Hugues Cabane ${ }^{6}$, Kheirreddine \\ Lebbou $^{1}$, Franck Levassort ${ }^{7}$, Kei Kamada $^{2}$, Akira Yoshikawa ${ }^{2}$, Mario Maglione ${ }^{8,9}$ \\ ${ }^{1}$ Université Lyon, Université Claude Bernard Lyon 1, CNRS, Institut Lumière Matière, UMR 5306, F-69100, \\ Villeurbanne, France \\ ${ }^{2}$ Institute of Materials Research, Tohoku University, 2-1-1 Katahira, Aoba-ku, Sendai, 980-8577, Japan \\ ${ }^{3}$ Université Grenoble Alpes, Institut Néel, F-38042 Grenoble, France \\ ${ }^{4}$ CNRS, Institut Néel, F-38042 Grenoble, France \\ ${ }^{5}$ Thales Research and Technology, 1, av. Fresnel, Campus de l'Ecole Polytechnique - F-91767 Palaiseau \\ Cedex, France \\ ${ }^{6}$ CristalInnov, Cleanspace, Parc d'Activités Alpespace, 354 voie Magellan, F-73800 Sainte Hélène du Lac, \\ France \\ ${ }^{7}$ University of Tours, GREMAN, UMR 7347 CNRS, INSA CVL, 26 Rue Pierre et marie Curie, 37100 Tours, \\ France \\ ${ }^{8}$ CNRS, ICMCB, UMR 5026, Pessac F-33600, France \\ ${ }^{9}$ Université de Bordeaux, ICMCB, UMR 5026, Pessac F-33600, France
}

KEY WORDS: Lead-free / Piezoelectrics / Micro-pulling down / Elemental segregation

ABSTRACT: $\mathrm{BaTiO}_{3}$-based crystal fibres with mm-sized grains were grown by the micropulling down technique from the $\mathrm{BaTiO}_{3}-\mathrm{CaTiO}_{3}-\mathrm{BaZrO}_{3}$ solid solution with pulling velocities about 6,9 and $15 \mathrm{~mm} \cdot \mathrm{h}^{-1}$. Natural growth direction was identified as $(001)_{\mathrm{pc}}$. For pulling velocities about $15 \mathrm{~mm} \cdot \mathrm{h}^{-1}$ and $9 \mathrm{~mm} \cdot \mathrm{h}^{-1}$, effective partition coefficients have been calculated from Castaing micro-probe measurements, and gave respectively 1.3 and 2 for $\mathrm{Zr}$, and 0.95 and 0.9 for Ca. Laser-Induced Breakdown Spectroscopy measurements reveal a strong inhomogeneity and variations of $\mathrm{Zr}$ contents while $\mathrm{Ca}$ contents show an opposite variation trend with a more steady distribution. Coexistence of two crystallized perovskite solid solutions is suggested. Most efficient polycrystals with mm-sized grain and $0.5 \mathrm{~mol} \% \mathrm{Zr}$ and $11 \mathrm{~mol} \% \mathrm{Ca}$ as average contents exhibit Curie temperature higher than $113^{\circ} \mathrm{C}$, electromechanical coupling factor $\mathrm{k}_{\mathrm{t}}$ up to $41 \%$ and piezoelectric charge coefficient $\mathrm{d}_{33}$ up to 242 pC. $\mathrm{N}^{-1}$ at room temperature. These values are similar to piezoelectric coefficients 
reported in literature for oriented flux-grown single crystals with close compositions. Both chemical and physical results obtained in BCTZ system make $\mu$-PD technique a promising way to improve the piezoelectric response of lead-free solid solution-based single crystals.

\section{Dedication}

This paper is respectfully dedicated to the memory of Shintaro Miyazawa, a pioneer in the development of Shaped Melt Lowering (SML) ${ }^{1}$ growth technique permitting effective partition coefficient $\mathrm{k}_{\text {eff }}=1$.

\section{Introduction}

Lead-based ferroelectric materials such as lead zirconate titanate $\mathrm{PbZr}_{1-\mathrm{x}} \mathrm{Ti}_{\mathrm{x}} \mathrm{O}_{3}(\mathrm{PZT})^{2,3}$ are the most widely used piezoelectrics because of their excellent properties. However, environmental and health issues of lead-based materials have led to an increasing interest in the development of lead-free piezoelectric materials ${ }^{4-8}$ whose the expected piezoelectric response is equal or higher than that of lead-based materials. While classical lead-free piezoelectric ceramics exhibit lower performance than PZT ceramics ${ }^{2,3}$, among the three main families of promising lead-free piezoelectrics ${ }^{4,7,9,10}$, recent reports have shown outstanding piezoelectric constants up to $620 \mathrm{pC} \mathrm{N}^{-1}$ in $(1-\mathrm{x}) \mathrm{BaTi}_{0.8} \mathrm{Zr}_{0.2} \mathrm{O}_{3^{-}}$ $\mathrm{xBa}_{0.7} \mathrm{Ca}_{0.3} \mathrm{TiO}_{3}$ (BCTZ) solid solution ${ }^{6,7,11,12}$. BCTZ solid solution properties make this system promising as alternative to lead-containing materials. Furthermore, single crystals, due to their anisotropic properties, usually display better electromechanical properties than those of ceramics. Hence, it is expected that BCTZ single crystals would exhibit piezoelectric constants of about 1500$2000 \mathrm{pC}^{-1}$ as predicted by Liu et al. ${ }^{11}$. Recently, growth attempt of BCTZ single crystals in $\mathrm{BaTiO}_{3^{-}}$ $\mathrm{CaTiO}_{3}-\mathrm{BaZrO}_{3}$ pseudo-ternary solid-solution were reported ${ }^{13-18}$ with various calcium (Ca) and zirconium $(\mathrm{Zr})$ contents. However, high partition coefficients have been measured in these single crystals grown by Top Seeded Solution Growth (TSSG) method ${ }^{15}$. This phenomenon induces strong elemental content variations within the crystals and is detrimental for their piezoelectric performances. As theoretically predicted by Burton et al. ${ }^{19}$, effective partition coefficients of elements depend on the growth rate. The growth velocities employed in the micro-pulling down ( $\mu-\mathrm{PD})$ technique, with an order of magnitude about $\mathrm{mm} \cdot \mathrm{min}^{-1}$, are substantially larger than those used for flux growth, which usually range within a few tenth of $\mathrm{mm} . \mathrm{h}^{-1}$. Hence, effective partition coefficients are expected to be different in between these two growth methods. Moreover, as experimentally referenced ${ }^{1,20,21}$, effective partition coefficients tend to be 1 in solid solutions and dopant distribution in oxides or semiconductors for high pulling speeds. 
In the present paper, to the best of our knowledge, we report for the first time the crystal growth by the $\mu$-PD technique of BCTZ solid solution. Two attempts performed at different pulling rates at $\mathrm{v}=9$ $\mathrm{mm} \cdot \mathrm{h}^{-1}$ then $\mathrm{v}=6 \mathrm{~mm} \cdot \mathrm{h}^{-1}$ for the first fibre and at $\mathrm{v}=15 \mathrm{~mm} \cdot \mathrm{h}^{-1}$ for second fibre are presented. BCTZ crystal habit and evolution of grains orientation towards single orientated crystal with (001) direction is highlighted via Laue pattern measurements along the as-grown crystal fibres. Longitudinal and transversal chemical characterizations of the fibres through Electron Probe Micro-Analysis (EPMA) were investigated. Substantial lower effective partition coefficients of $\mathrm{Ca}$ and $\mathrm{Zr}$ in $\mu$-PD grown crystals were calculated and discussed with those calculated in already reported ${ }^{15}$ TSSG-grown crystals. Strong chemical inhomogeneity is highlighted through Laser-Induced Breakdown Spectroscopy (LIBS). Dielectric and piezoelectric measurements performed on sub-centimetric polycrystals with millimetre-sized grains are presented and their electromechanical performances are compared to the those of orientated single crystals with close compositions reported in the literature $^{17,18}$.

\section{Experimental procedure}

\subsection{Chemical and physical analysis}

Castaing Electron Probe Microscopy Analysis (EPMA) were performed with a CAMECA SX-100 apparatus with a wavelength dispersive spectrometer working at $15 \mathrm{kV}$. Reference samples ${ }^{14}$ for quantitative analysis of elements were chosen in order to reach an experimental relative accuracy of $\Delta \% \mathrm{Zr}=\Delta \% \mathrm{Ca}= \pm 0.3 \mathrm{~mol} . \%$ per single analysis point in the investigated concentrations range.

LIBS-based imaging setup was used to image the distribution of $\mathrm{Ca}$ and $\mathrm{Zr}$ in the different sections of as-grown fibres. LIBS is an all-optical analytical technique, allowing the mapping of metallic elements in various type of solid matrices ${ }^{22-24}$. During the analysis, the sample surface is scanned, through single laser pulses, in a pixel-by-pixel manner inducing the breakdown and sparks of the material. The light radiation emitted by the plasma is collected by an optical system and analysed using a spectrometer equipped with an intensified charge-coupled device (ICCD) camera. BCTZ samples were analysed using Nd:YAG laser with pulse energy of about $600 \mu \mathrm{J}$ operating at $100 \mathrm{~Hz}$, and a lateral resolution (i.e. distance between two consecutive laser shots) of $12 \mu \mathrm{m}$. The spectrometer was configured in the spectral range from $310 \mathrm{~nm}$ to $350 \mathrm{~nm}$ in order to detect intense lines of both $\mathrm{Ca}$ (318.6 nm) and $\mathrm{Zr}(343.8 \mathrm{~nm})$. The intensity calibration of the LIBS intensities was performed from the profiles obtained with EPMA.

The dielectric and piezoelectric measurements were performed on samples, which were poled under DC electric field by the increasing field method (up to 1.5 or $2 \mathrm{kV} . \mathrm{cm}^{-1}$ ) at room temperature. Prior poling samples were prepared by electroding the major faces of crystals using silver paste. The 
piezoelectric properties were recorded with an impedance analyzer (4294A Agilent) $24 \mathrm{~h}$ after poling. The $d_{33}$ values were measured by Berlincourt method with a Pennebaker Piezo $d_{33}$ meter (Model 8000). The temperature dependence of dielectric constant and dielectric losses were characterized in order to determine temperature phase transitions. The experiment were realized using an environmental chamber (Pyrox), which allows to measure the dielectric constants every $2^{\circ}$ between $40{ }^{\circ} \mathrm{C}$ to $180^{\circ} \mathrm{C}$ at $1 \mathrm{kHz}$.

Electromechanical parameters of the thickness mode were deduced from the measurement of the complex electrical impedance as a function of the frequency around the fundamental thickness-mode resonance. The experimental setup was composed of an HP4395 spectrum analyzer (Agilent Technologies Inc., Palo Alto, CA) with its impedance test kit and specific spring clamping. For the corresponding theoretical simulations of the electrical impedance, the Krimholtz-Leedom-Matthaei (KLM) model ${ }^{25,26}$ was used. This one-dimensional model is based on an equivalent electrical circuit scheme allowing a numerical calculation of a multilayer structure behavior including the piezoelectric layer and the two electrodes. Identifications of the effective thickness coupling factor $\left(k_{t}\right)$ and the relative dielectric permittivity at constant stress $\left(\varepsilon_{33}^{T}\right)$ are performed with a fitting process of the experimental complex electrical impedance. The two other electromechanical coupling coefficients for the transverse modes $\left(\mathrm{k}_{31}\right.$ and $\left.\mathrm{k}_{32}\right)$ were determined from the measurement of the resonant $\left(\mathrm{f}_{\mathrm{r}}\right)$ and antiresonant $\left(\mathrm{f}_{\mathrm{a}}\right)$ frequencies on the basis of IEEE standards ${ }^{27}$.

X-ray diffraction (XRD) patterns were collected on a Bragg-Brentano $\theta-\theta$ geometry diffractometer Bruker D8 Advance working with $\mathrm{Cu}$ anticathode $(40 \mathrm{kV}, 40 \mathrm{~mA}), 0.3^{\circ}$ slits and Ni filter. The data were collected over an angular range of $2 \theta=5^{\circ}-90^{\circ}$ with a $0.006^{\circ}$ step. XRD patterns were studied using the known space groups of $\mathrm{BaTiO}_{3}{ }^{28}$. Using a conventional notation for perovskite compounds, the pseudo-cubic Miller indices will be hereafter written using "pc" indices.

Laue back-scattering patterns were recorded using an Image Plate (Fujifilm) sensor after a 16-minute stationary crystal irradiation with a collimated $(0.7 \mathrm{~mm})$ polychromatic X-ray beam supplied by a tungsten anticathode working at $35 \mathrm{kV}$ and $40 \mathrm{~mA}$ (Seifert ID3003 generator). The polished samples were held on a goniometric head and set perpendicular to the X-ray beam using an autocollimator. OrientExpress software ${ }^{29}$ was used for pattern indexing.

\subsection{Synthesis and crystal growth}

Synthesis of initial load was prepared from $\mathrm{BaCO}_{3}, \mathrm{CaCO}_{3}, \mathrm{TiO}_{2}, \mathrm{ZrO}_{2}$ raw powders with $99.99 \%$ purity from Fox Chemicals GmbH. Based on previous works ${ }^{13-15}$, growth attempts were carried out with a self-flux composed of an excess of $\mathrm{CaO}$ and $\mathrm{TiO}_{2}$. As for $\mathrm{BaTiO}_{3}$ growth ${ }^{30,31}$, the thermodynamics effect due to fluxes $\mathrm{CaO}$ and $\mathrm{TiO}_{2}$ aims at decreasing the crystallization temperature of BCTZ solid phase with respect to effective partition coefficients of elements. Initial load with 
$\left(\mathrm{Ba}_{0.883} \mathrm{Ca}_{0.117}\right)\left(\mathrm{Ti}_{0.996} \mathrm{Zr}_{0.004}\right) \mathrm{O}_{3}$ exact composition represents the global solid solution including the solvent and the solute to be grown. So that $100 \%$ of $\mathrm{Ba}$ and $\mathrm{Ca}$ cations are in A site and $100 \%$ of $\mathrm{Ti}$ and $\mathrm{Zr}$ cations are in $\mathrm{B}$ sites of the $\mathrm{ABO}_{3}$ perovskite structure.

Crystal growth was performed using the micro-pulling down technique ${ }^{32-35}$. BCTZ single crystal fibres were pulled from inductively heated iridium crucible which is placed on an iridium after-heater and surrounded by a zirconia and alumina ceramics assembly located in a gas proof tubular silica chamber $^{32-35}$. Early attempts were undertaken with a conical-shaped iridium crucible with a $600-\mu \mathrm{m}$ capillary at its bottom. Contrary to liquid $\mathrm{TiO}_{2}$, which exhibits a poor wettability ${ }^{36}$ and acts, here, as the main part of the self-flux, we observed that BCTZ liquid solution displays a high wettability. This leads to severe creeping of the solution along the outer surface of the crucible (Figure 1a to d) whatever the heating powers used until load solidification within the crucible. Therefore, a crucible with a 3-mm wide cylindrical die with 5 openings has been chosen with a concave shape at its bottom in order to prevent the solution creeping (Figure 1e to h). Two growth experiments were carried out in Ar- $\mathrm{O}_{2}\left(2 \%\right.$ vol.) atmosphere at different pulling rates $\mathrm{v}=15 \mathrm{~mm} \cdot \mathrm{h}^{-1}$ for the first fibre and $\mathrm{v}=9 \mathrm{~mm} \cdot \mathrm{h}^{-1}$ then to $\mathrm{v}=6 \mathrm{~mm} \cdot \mathrm{h}^{-1}$ for the second fibre. As no BCTZ seeds was available with sufficient length, growths were performed onto an iridium rod with a needle-shaped tip.

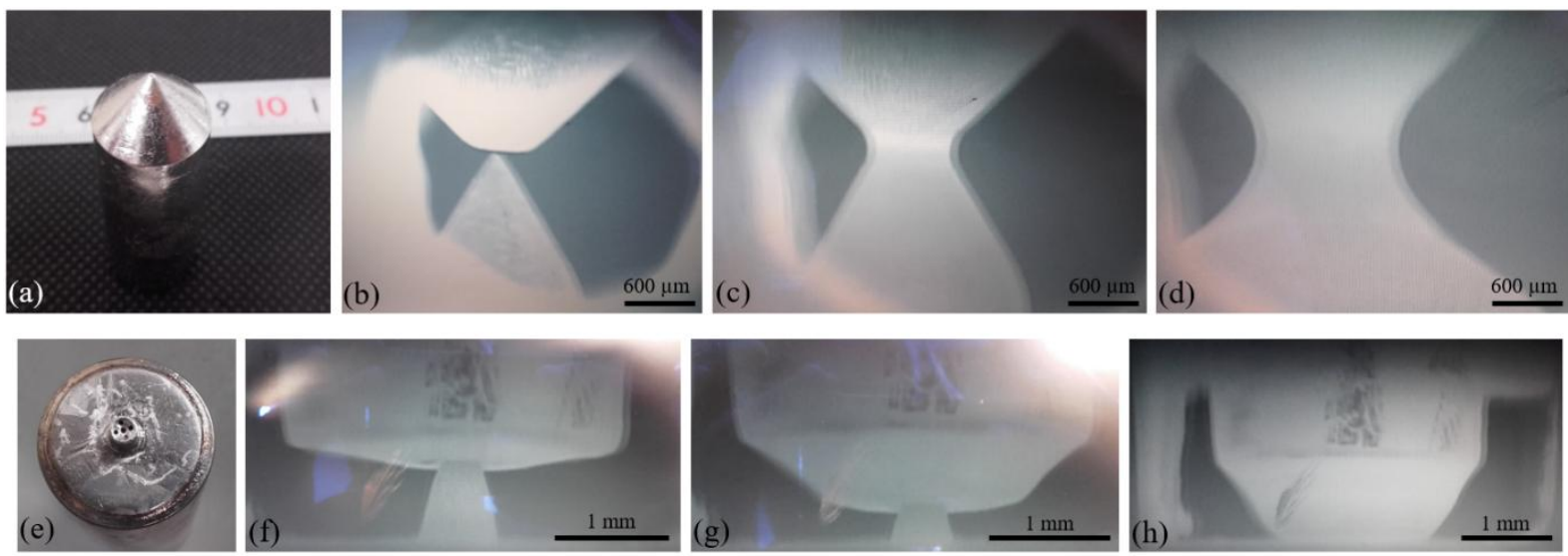

Figure 1 : (a) Conical-shaped iridium crucible with a 600-um capillary die; (b) Ir rod with needle-shaped tip and Ir conical crucible before connexion; (c) Connexion of the Ir rod with the liquid solution and (d) creeping of the liquid solution along the outer surface of the Ir conical crucible. (e) Iridium crucible with a 3-mm wide cylindrical die, with a concave end and 5 capillary holes; (f) Connection of the Ir rod with the liquid solution; $(g)$ and $(h)$ : beginning of pulling. No liquid solution creeping is observed.

\section{Results and discussion}

\subsection{Longitudinal chemical analysis of as-grown fibres}

Centimetre-sized fibres were obtained (Figure 2). The dark colour of BCTZ fibres is assumed to be induced by the partial pressure of $\mathrm{O}_{2}(2 \mathrm{vol} . \%)$ used in the silica growth chamber as previously observed on air-annealed BCTZ single crystals with similar compositions ${ }^{15}$. It corresponds thus to the natural colour of stoichiometric $\mathrm{BCTZ}$ single crystals similar to those of $\mathrm{BaTiO}_{3}{ }^{30,31}$ and $\mathrm{CaTiO}_{3}{ }^{37}$ single crystals while $\mathrm{BaZrO}_{3}{ }^{38}$ crystals are colourless. Unlike $\mu$-PD congruent melting crystals ${ }^{39-43}$ grown with a steady diameter at constant temperature, we noted a decreasing of the BCTZ freezing temperatures inducing the diameter shrinking at constant temperature as the first fibre pulling proceed 
(Figure 2a). This is correlated to the slopes of the liquidus and solidus curves of BCTZ phase diagram, which is assumed to be similar to $\mathrm{BaTiO}_{3}-\mathrm{CaTiO}_{3}$ system ${ }^{44}$ due to the low $\mathrm{Zr}$ content employed (i.e. $0.4 \mathrm{~mol} . \%$ ) in the present work. Therefore, an accurate decreasing ramp of the heating power was achieved in order to maintain a constant diameter. We note that diameter variation as well as meniscus height variation, which could varies up to $2 \mathrm{~mm}$, as observed for the first fibre pulled at v=15mm. $\mathrm{h}^{-1}$ (Figure 2a), lead to a Peclet number much higher than 1, featuring thus the Marangoni convection as the dominating transport mechanism ${ }^{45}$. A more tricky decreasing heating power process was achieved for lower pulling velocities at $\mathrm{v}=6 \mathrm{~mm} \cdot \mathrm{h}^{-1}$. Except a drop-melt at the early stage of the crystal growth induced by a slight overheating of the liquid solution, a second fibre with a nearly constant 3-mm diameter has been obtained (Figure $2 b$ ).
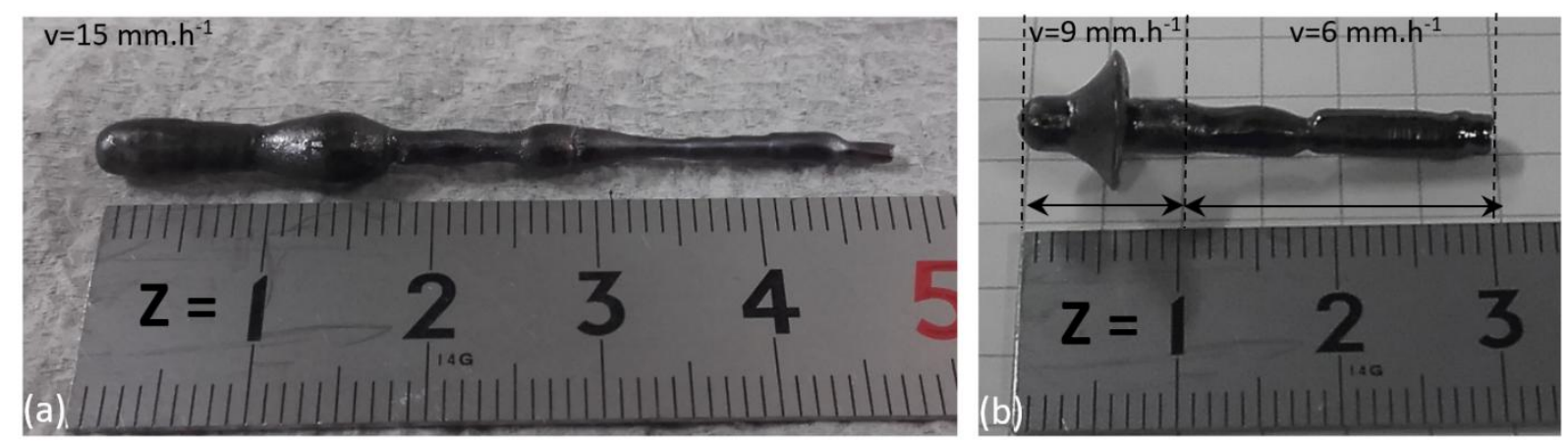

Figure 2 : Fibres obtained at pulling rates: (a) $v=15 \mathrm{~mm} \cdot \mathrm{h}^{-1}$, (b) $v=9 \mathrm{~mm} \cdot \mathrm{h}^{-1}$ in the first part from $Z=0$ to $Z=10 \mathrm{~mm}$ and $v=6$ $\mathrm{mm} \cdot \mathrm{h}^{-1}$ in the second part from $Z=10$ to $Z=30 \mathrm{~mm}$.

EPMA longitudinal chemical analysis performed at the centre along the fibre axis revealed fluctuations of chemical contents with, nonetheless, a nearly steady evolution of the average $\mathrm{Ca}$ and $\mathrm{Zr}$ contents all along the fibre grown at $\mathrm{v}=15 \mathrm{~mm} \cdot \mathrm{h}^{-1}$ (Figure 3a). Chemical fluctuations are attributed to thermal instabilities and the large-sized meniscus height, which have a pronounced effect on the chemical segregation in the longitudinal direction during the micro-pulling down process ${ }^{45}$. On the contrary, the end of the second fibre grown with a lower pulling velocity $\mathrm{v}=6 \mathrm{~mm} \cdot \mathrm{h}^{-1}$ shows lower chemical fluctuations suggesting a steadier growth as featured by the constant $3-\mathrm{mm}$ wide diameter (Figure $3 b$ ). However, $\mathrm{Ca}$ and $\mathrm{Zr}$ contents, respectively, increases and decreases more strongly with respect to the pulled length (Figure $3 \mathrm{~b}$ ). They follow the same segregation trend but in a lower extent than those measured in TSSG-grown crystals ${ }^{15}$. Indeed, effective partition coefficients have been calculated from EPMA analysis performed at the early beginning of both fibres for $\mathrm{v}=9 \mathrm{~mm} \cdot \mathrm{h}^{-1}$ and $\mathrm{v}=15 \mathrm{~mm} \cdot \mathrm{h}^{-1}$ and give respectively, 0.90 and 0.95 for $\mathrm{Ca}, 2.5$ and 1.3 for $\mathrm{Zr}$. We emphasize thus they depends on the growth velocity employed for BCTZ system (Figure 4). 

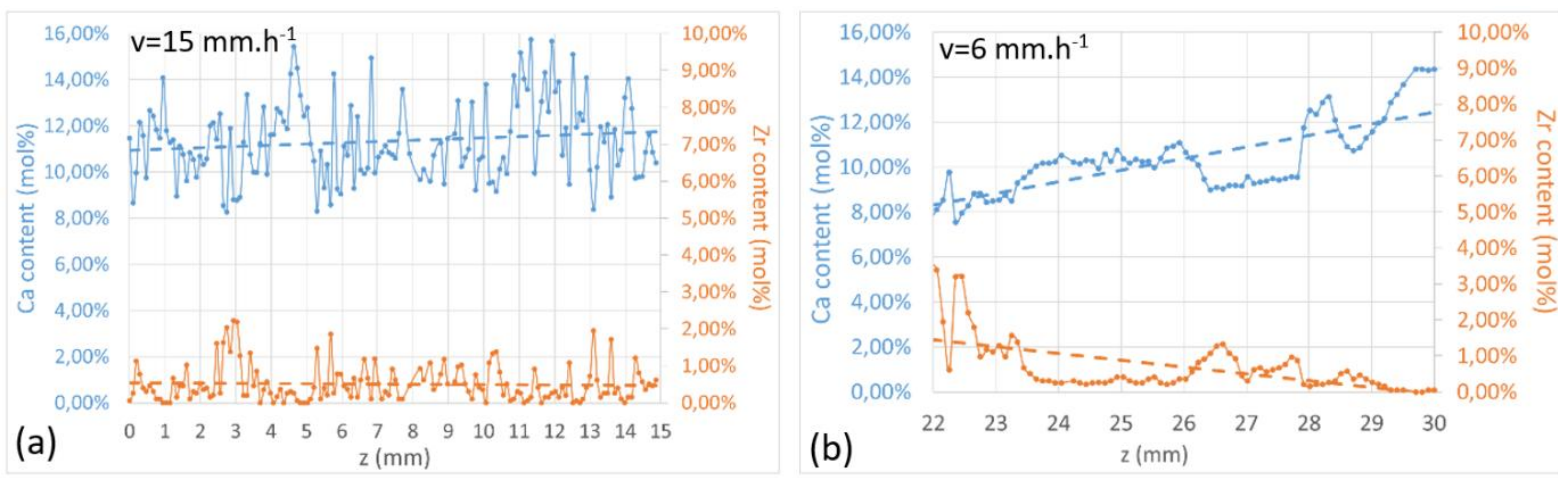

Figure 3 : Ca and Zr longitudinal content profile as a function of length of fibres pulled at (a) $v=15 \mathrm{~mm} \cdot \mathrm{h}^{-1}$ (from $z=0.0$ to $15.1 \mathrm{~mm}$ ) and (b) $v=6 \mathrm{~mm} \cdot \mathrm{h}^{-1}$ (from $z=21.9$ to $30.0 \mathrm{~mm}$ ). Dashed lines display the average Ca and $\mathrm{Zr}$ contents.
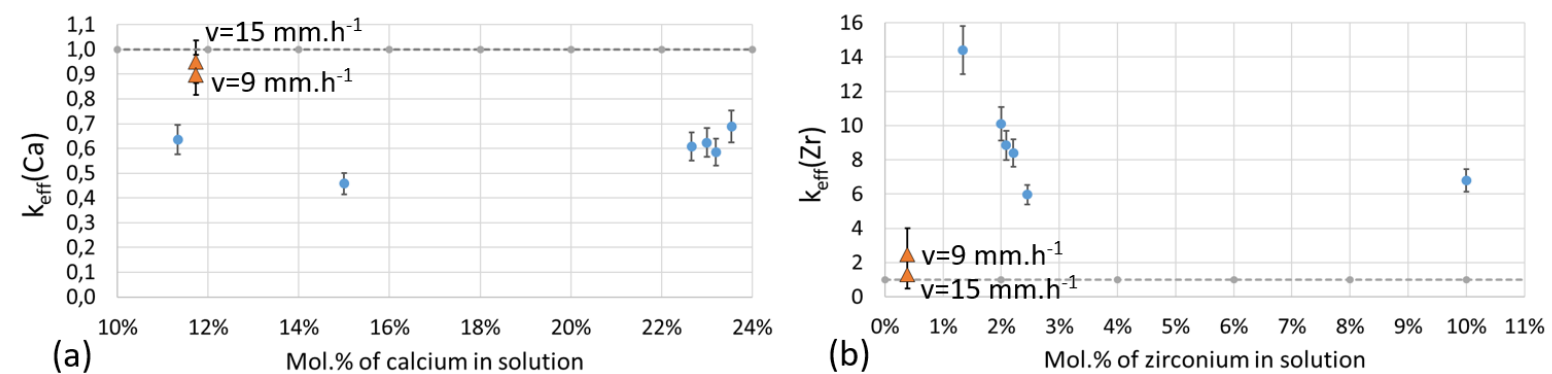

Figure 4 : Effective partition coefficients of $\mu-P D$ grown fibres (orange triangles) compared to effective partition coefficient reported for flux grown crystals ${ }^{15}$ (blue circles) for (a) Ca and (b) Zr. Dashed grey lines display targeted $k_{\text {eff }}=1$.

LIBS chemical imaging calibrated with respect to EPMA measurements overall the surface of polished samples highlighted the distribution of $\mathrm{Ca}$ and $\mathrm{Zr}$ elements in the fibres (Figure 5). While $\mathrm{Ca}$ distribution evolves roughly smoothly, $\mathrm{Zr}$ content follows either erratic distribution with sharp concentration drops at high pulling speed and it segregates along well-defined streaky stripes with several hundred micrometres size, more particularly at lower pulling velocities (Figure 5). Some stripes exhibit high and non-uniform $\mathrm{Zr}$ content whereas the other ones exhibit a low $\mathrm{Zr}$ content. Due to the very high thermal gradients ${ }^{46-50}$ (ranging in between 200 and $500^{\circ} \mathrm{C} \cdot \mathrm{mm}^{-1}$ at the nozzle of the die) and fast pulling velocities employed with $\mu$-PD technique, we assume a simultaneous crystallization of two demixing perovskite solid solutions from a two-phase region of the BCTZ phase diagram, as existing in $\mathrm{BaTiO}_{3}-\mathrm{CaTiO}_{3}$ system ${ }^{44}$ below $1595^{\circ} \mathrm{C}$. Indeed, this temperature is typically in the temperature range where the $\mu$-PD growths occurred regarding the pyrometric measurements $\left(\sim 1485^{\circ} \mathrm{C}\right.$ to $\left.1570^{\circ} \mathrm{C}\right)$ performed on saturation temperatures in this system where a spinodal decomposition at high temperature has been highlighted with BCTZ flux-grown crystals ${ }^{15}$.

On the one hand, stripes cannot be ascribed to potential eutectic lamellar microstructure which is usually observed, in the order of few micrometres, at eutectic composition in pseudo-binary, or beyond, systems ${ }^{51}$. Eutectic composition in $\mathrm{BaTiO}_{3}-\mathrm{CaTiO}_{3}$ system corresponds to the chemical formula $\mathrm{Ba}_{0.77} \mathrm{Ca}_{0.23} \mathrm{TiO}_{3}(\mathrm{BCT})$. Considering the low $\mathrm{Zr}$ content in the crystals of the present work, we can reasonably assume that the eutectic composition in BCTZ system is close to this composition. The BCT eutectic composition, which melts congruently, has been grown by Czochralski ${ }^{52}$ and Laser Heated Pedestal Growth ${ }^{53}$. In the latter, similar or higher thermal gradients can be achieved such as 
those established with the in micro-pulling down technique. In both cases, as-grown single crystals are clear and transparent and do not present any streaky growth or series of stripes.

On the other hand, as well-known, $\mathrm{Ca}$ and $\mathrm{Ba}$ cations can only enter A-site of the $\mathrm{ABO}_{3}$ perovskite matrix, $\mathrm{Zr}$ and $\mathrm{Ti}$ cations can only enter the B-site. For instance, when $\mathrm{Zr}$ content increases in the crystal, Ti content automatically decreases, because of same crystallographic site occupation. However, an increasing of $\mathrm{Ca}$ content within crystals simultaneously to the decreasing of $\mathrm{Zr}$ content is not self-explanatory regarding the crystallographic sites. So that, the only thermodynamic possibility is the existence of two solid solutions, which have crystallized below the spinodal surface. Hence, the crystallization path does not follow the at-equilibrium liquidus and solidus surfaces as for steady fluxgrowth. The crystallization path for high pulling speed $\left(15 \mathrm{~mm} \cdot \mathrm{h}^{-1}\right)$ crosses more or less vertically the phase diagram for reaching directly a two-phase region due to the high thermal gradient in the mmsized meniscus. This led to effective partition coefficients closer to 1 than those reported for steady flux-grown crystals. Concerning the crystallization path for lower pulling speed $\left(6 \mathrm{~mm} \cdot \mathrm{h}^{-1}\right)$, we assume that the thermodynamic path follow a steep out-of-equilibrium liquidus surface, leading to different effective partition coefficients which tend, in some extent, to get closer to those calculated with fluxgrown crystals close to the equilibrium. Besides, it is worth noticing that $\mathrm{BaTiO}_{3}-\mathrm{CaTiO}_{3}$ phase diagram does not exactly correspond to the real phase diagram where the growth took place. Indeed, $\mathrm{BaTiO}_{3}-\mathrm{CaTiO}_{3}-\mathrm{BaZrO}_{3}$ phase diagram must be slightly different because of the little $\mathrm{Zr}$ amount (i.e. $0.4 \mathrm{~mol} . \%$ ) in the liquid solution. So that the spinodal surface should be slightly modified. Nevertheless, the low amount of $\mathrm{Zr}$ employed allows us to consider that both phase diagrams should exhibit the same main features.

We conclude that the effective segregation phenomenon in BCTZ grown by $\mu$-PD is not completely compensated by the fast kinetics of the growth in between 6 and $15 \mathrm{~mm} \cdot \mathrm{h}^{-1}$ but they are drastically reduced compared to those measured in TSSG-grown crystals. Higher pulling rate should be applied in order to reach partition coefficients equal to 1 as observed for the Edge-defined Film-fed Growth of $\mathrm{LiNb}_{\mathrm{x}} \mathrm{Ta}_{1-\mathrm{x}} \mathrm{O}_{3}$ solid solution where a pulling speed about $42 \mathrm{~mm} \cdot \mathrm{h}^{-1}$ was used and as calculated for $\mu \mathrm{PD}$-grown $\mathrm{Ti}^{3+}: \mathrm{Al}_{2} \mathrm{O}_{3}$ crystals ${ }^{54}$ in order to achieve a constant $\mathrm{Ti}^{3+}$-dopant distribution. Nevertheless, it appears that it would be at the expense of chemical homogeneity throughout the BCTZ samples. 


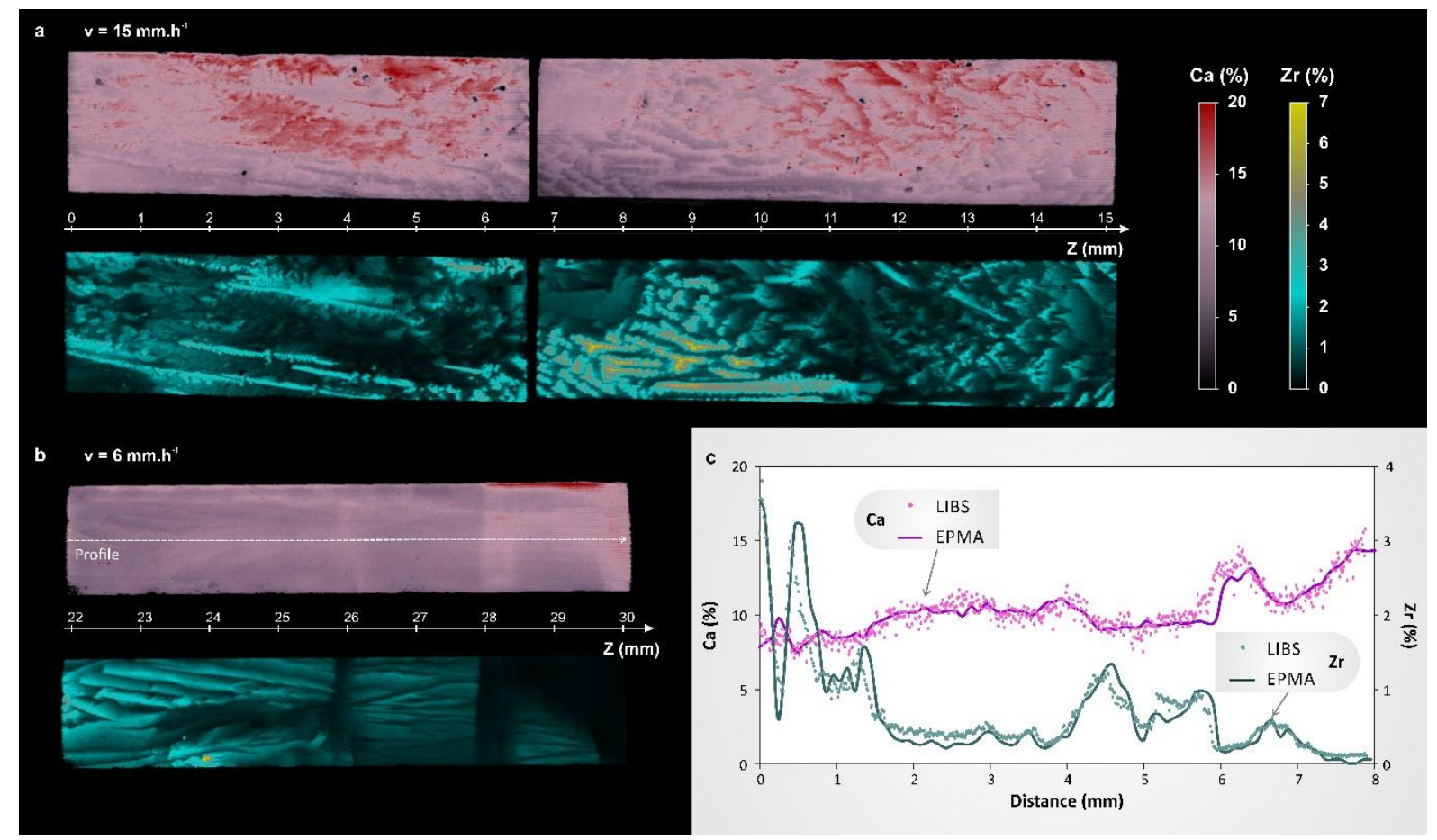

Figure 5 : LIBS chemical imaging for Ca and Zr on samples obtained from fibres pulled at (a) $15 \mathrm{~mm} \cdot \mathrm{h}^{-1}$ and (b) $6 \mathrm{~mm} \cdot \mathrm{h}^{-1}$. (c) Molar contents have been normalized regarding EPMA profile performed along the dashed line of the fibres grown at $6 m m \cdot h^{-1}$

\subsection{Transversal chemical analysis of as-grown fibres}

Transversal chemical analysis on two $3-\mathrm{mm}$ wide cross sections located at $19 \mathrm{~mm}$ and $27 \mathrm{~mm}$ of the fibre pulled at $6 \mathrm{~mm} \cdot \mathrm{h}^{-1}$ depicted on Figure 2 were performed by both EPMA (Figure 6) and LIBS (Figure 7).

Elemental segregation phenomenon is also observed where the core of the fibre is Zr-rich contrary to its periphery, which is Ca-rich. This trend is similar to that which is observed in TSSG-grown BCTZ crystals ${ }^{15}$ or in rare earth-doped garnet ${ }^{41,55-57}$ grown by $\mu$-PD where strong increasing or decreasing of dopant content is observed from the rim towards the core of fibres.
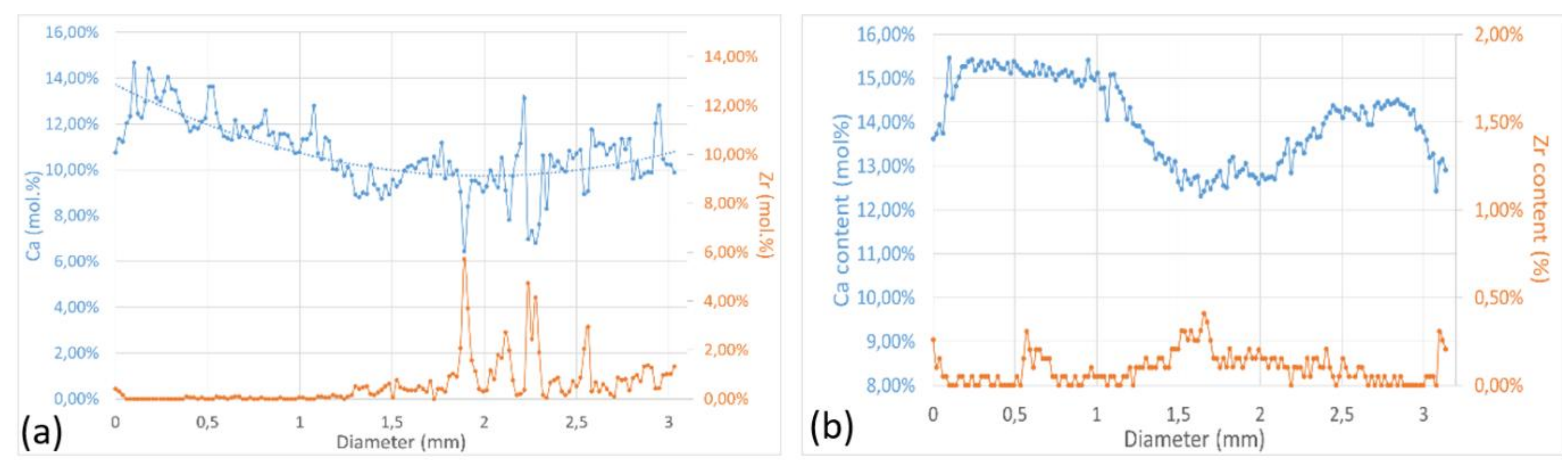

Figure 6: EPMA transversal chemical analysis for Ca and Zr in two cross section of 3-mm wide fibres pulled at $6 \mathrm{~mm} . \mathrm{h}^{-1}$ at (a) $z=19 \mathrm{~mm}$ (Dashed lines display the average transversal Ca content) and at (b) $z=27 \mathrm{~mm}$

LIBS confirmed this phenomenon where central zone exhibits $\mathrm{Zr}$-rich and Ca-poor contents whereas the other zones, at the rim of the fibre, display the reverse tendency. 

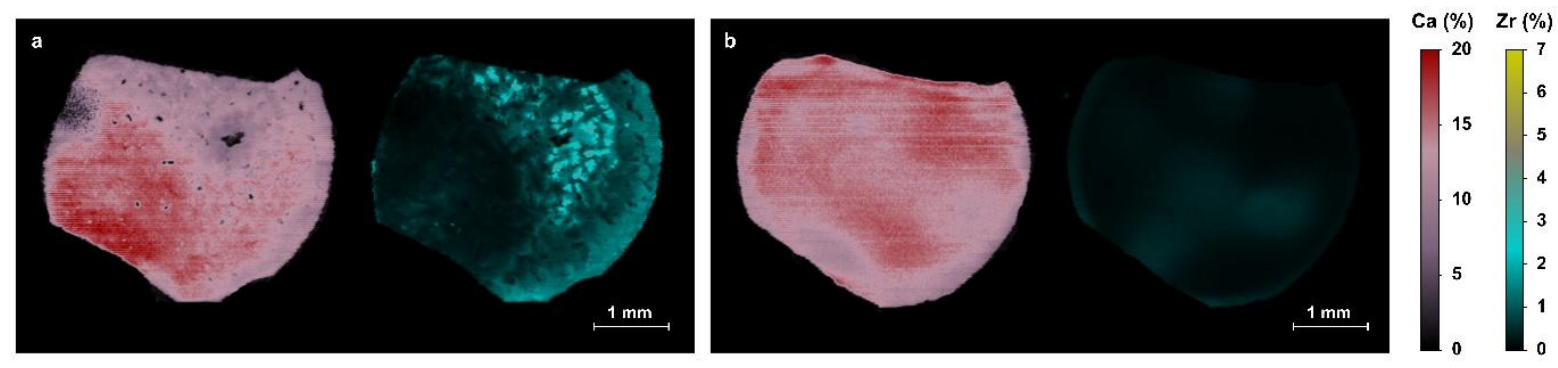

Figure 7 : LIBS transversal chemical imaging for Ca and Zr obtained on two cross sections of a 3-mm wide fibre pulled at $6 \mathrm{~mm} \cdot \mathrm{h}^{-1}$ and located at (a) $Z=19 \mathrm{~mm}$ and $(b) Z=27 \mathrm{~mm}$

\subsection{X-rays diffraction and Laue analysis}

Several XRD patterns recorded (Figure 8) on crushed samples displayed invariably perovskite tetragonal structure with very close lattice parameters due to the close sample compositions and the slight broadening of the peaks induced by the inhomogeneity of the elemental content as revealed by LIBS measurements in the whole analysed sample volume. Note that the peak foot detected only around the strongest line (101), around $2 \theta=31^{\circ}$, is an experimental artefact induced by the saturation of Ni filter used in the XRD apparatus (see 3.1). Moreover, difference of peak relative intensity is ascribed to preferential orientation of some grains in the slight amount of powder, which was analysed for each sample. Typically, lattice parameters about $\mathrm{a}=3.9881 \AA$ and $\mathrm{c}=4.0174 \AA$ were calculated in the middle of fibre $\mathrm{n}^{\circ} 1$ in accordance with tetragonal phase. 

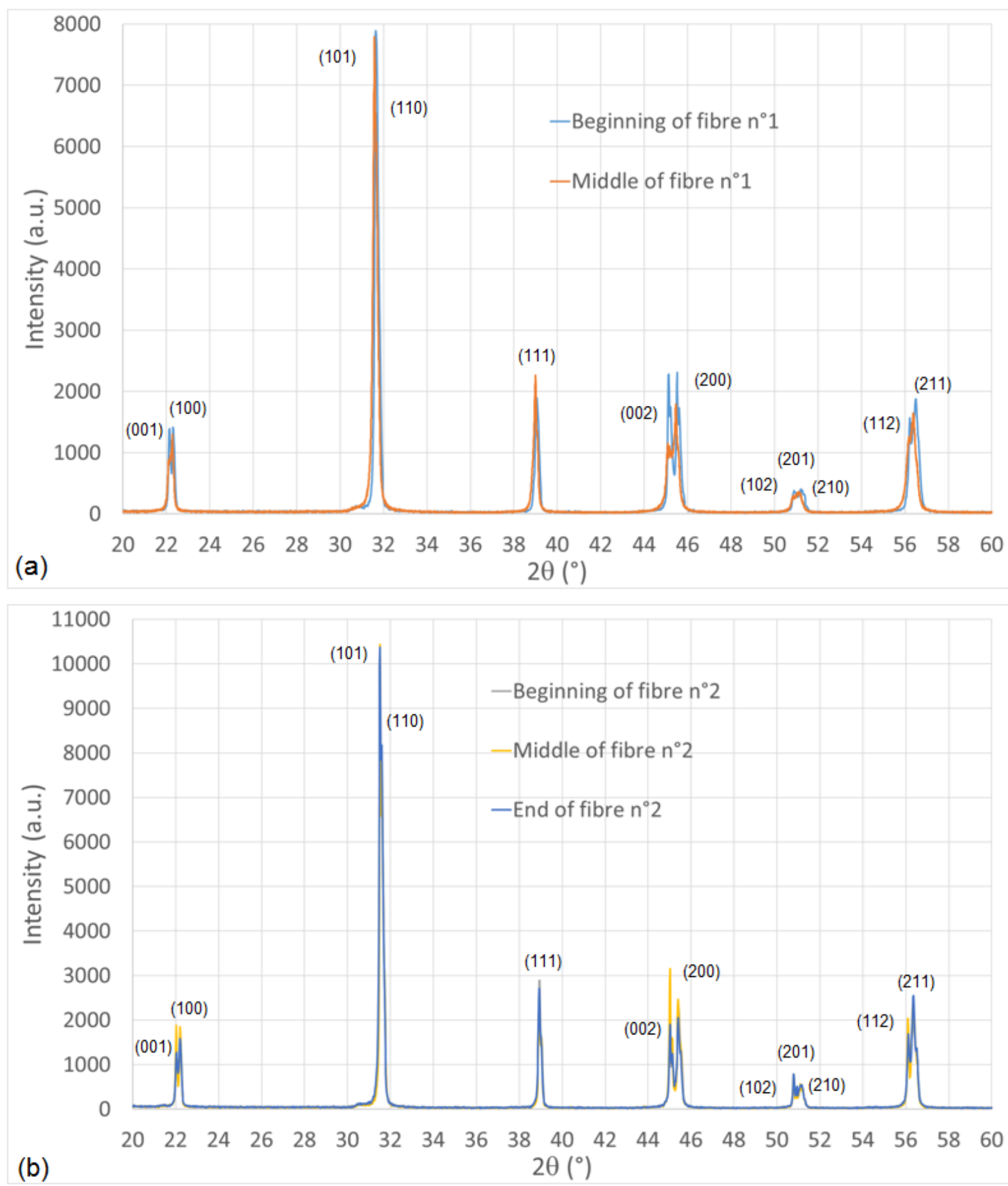

Figure 8 : XRD patterns on BCTZ crushed sample exhibiting a tetragonal structure with double peaks at $2 \theta \sim 45^{\circ}$ featuring (002) and (200) crystallographic plans for (a) fibre $n^{\circ} 1$ and (b) fibre $n^{\circ} 2$.

Laue patterns were recorded on different sample locations all along the fibres. Experimental patterns were indexed with $\mathrm{P} 4 \mathrm{~mm}$ space group and lattice parameters above mentioned. As growth attempts were performed on Ir rods, the beginning of fibres exhibits invariably a highly polycristalline structure with micrometre-sized grains. As the pulling length increases, sub mm-sized grains arises with preferential orientation along (110) $)_{\mathrm{pc}}$ and $(001)_{\mathrm{pc}}$ directions (Figure 9a and b). Finally, the end of fibres exhibit large mm-sized single crystal grains with predominantly $(001)_{\mathrm{pc}}$ orientation (Figure $9 \mathrm{~b}$ and c), 
which corresponds, unsurprisingly, to the more stable growth orientation usually used for the crystal growth in perovskite systems ${ }^{58}$.
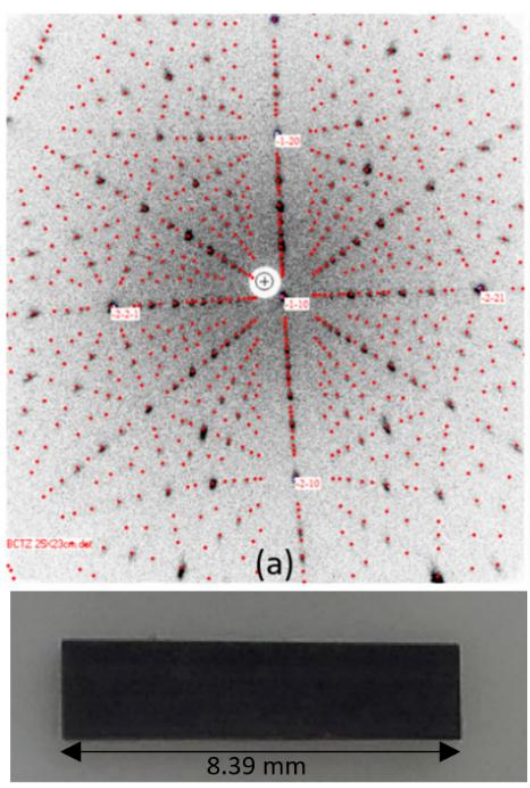

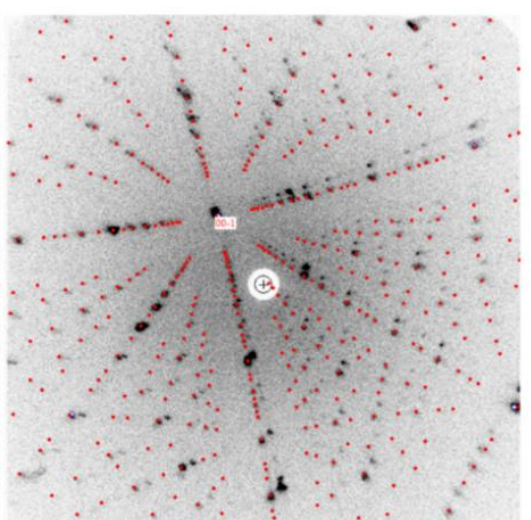

(b):

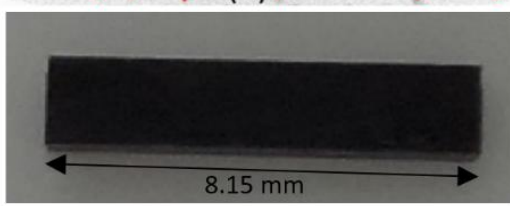

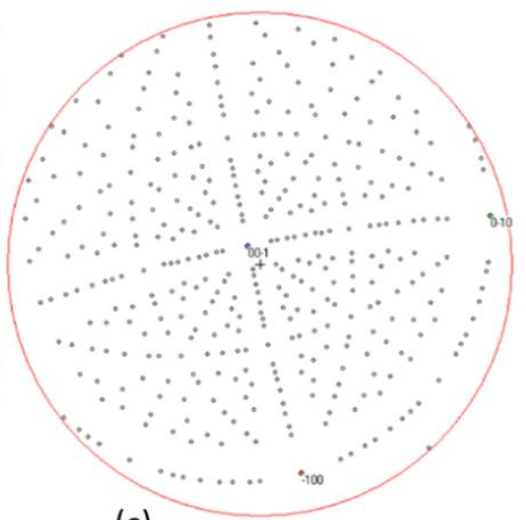

(c)

Figure 9 : Laue patterns along growth direction: (a) mm-sized grains displaying (110) $)_{p c}$ orientation in the middle of fibre $n^{\circ} 1$ and (b) two grains slightly tilted with both (001) $)_{p c}$ orientation at the end of fibre $n^{\circ} 2$. (c) Stereographic projection along $(001)_{p c}\left(\right.$ end of fibre $\left.n^{\circ} 2\right)$

It is worth mentioning that stripes highlighted by LIBS characterization tend to be oriented along $(001)_{\mathrm{pc}}$ direction. As Laue patterns were recorded with a circular $0.7 \mathrm{~mm}$-wide beam on zones containing both Zr-rich stripes and Zr-poor stripes, they displayed clearly single crystal features. These features indicate that the significant drops and variations of $\mathrm{Ca}$ and $\mathrm{Zr}$ contents from one stripe to another do not affect considerably the single crystal nature of the analysed zones. On the one hand, Laue experiments confirm the crossover of the BCTZ solid solution across a wide range of compositions as previously reported ${ }^{13}$. On the other hand, the presence of two solid solutions remains not excluded. Indeed, two solid solutions can grow each on the other with good lattice-matched epitaxy because of their close compositions, as already seen in lead-free systems with Morphotropic Phase Boundary,7,59-61 and Phase Convergence Region ${ }^{6,11}$. Nevertheless, they would be undistinguishable on Laue patterns due to their very similar lattice parameters and structures ${ }^{15}$ as well as their mixing at the nanometre scale ${ }^{62-64}$.

\subsection{Dielectric and electromechanical characterization}

Five polycrystalline sub-centimetre-sized samples with large millimetre-sized grains were analysed. The sample size is : $\mathrm{n}^{\circ} 1\left(6,68 \times 2,08 \times 0,66 \mathrm{~mm}^{3}\right), \mathrm{n}^{\circ} 2\left(8,39 \times 2,06 \times 0,63 \mathrm{~mm}^{3}\right), \mathrm{n}^{\circ} 3(3,58 \times 1,71 \mathrm{x}$ $\left.0,52 \mathrm{~mm}^{3}\right), \mathrm{n}^{\circ} 4\left(9,81 \times 1,47 \times 0,47 \mathrm{~mm}^{3}\right)$ and $\mathrm{n}^{\circ} 5\left(8,15 \times 1,61 \times 0,72 \mathrm{~mm}^{3}\right)$. As highlighted by LIBS measurements, samples are chemically inhomogeneous. So that sample compositions are given for information purposes only in Table 1. That illustrates a macroscopic trend of their average content, 
which nevertheless allows it to be corroborated to their macroscopic electromechanical behaviour since their ferroelectric and piezoelectric features reflect long-range order effects. Dielectric measurements performed at various frequency confirm the pure ferroelectric behaviour and the tetragonal structure at room temperature of BCTZ samples as illustrated on Figure 10 with sample $\mathrm{n}^{\circ} 1$ with $\left(\mathrm{Ba}_{0.889} \mathrm{Ca}_{0.111}\right)\left(\mathrm{Ti}_{0.995} \mathrm{Zr}_{0.005}\right) \mathrm{O}_{3}$ average macroscopic composition. For this sample, the Tetragonal-Cubic transition (T-C) is observed at $113^{\circ} \mathrm{C}$ and the Orthorhombic-Tetragonal (O-T) transition near to $-20^{\circ} \mathrm{C}$.

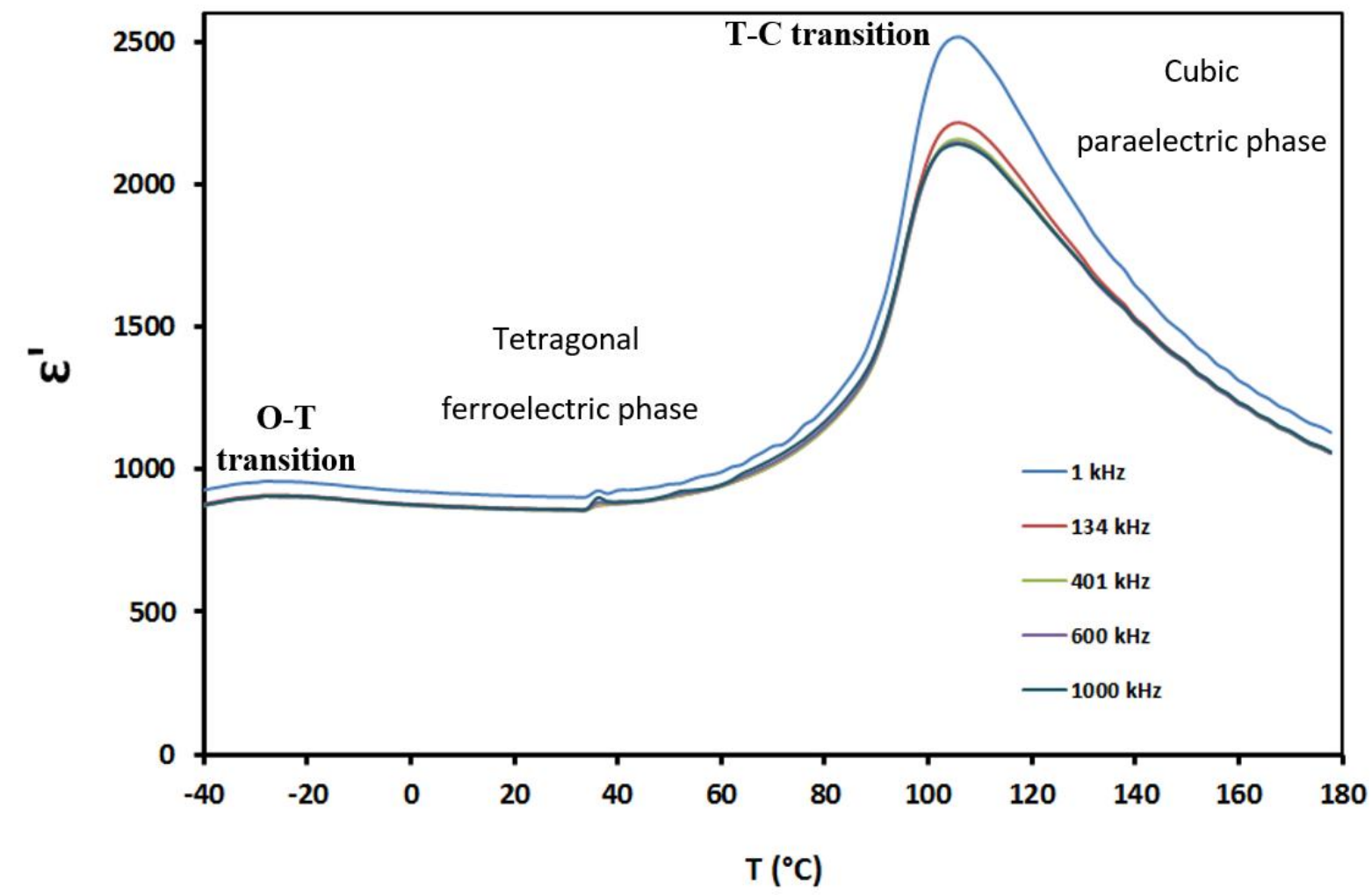

Figure 10 : Dielectric constants measurements at various frequencies of poled sample $n^{\circ} 1$ with $\left(\mathrm{Ba}_{0.889} \mathrm{Ca}_{0.111}\right)\left(\mathrm{Ti}_{0.995} \mathrm{Zr}_{0.005}\right) \mathrm{O}_{3}$ average composition. $T$-C and $O-T$ correspond to, respectively, tetragonal-cubic transition at $113^{\circ} \mathrm{C}$ and orthorhombictetragonal phase transition at $-20^{\circ} \mathrm{C}$.

\begin{tabular}{|c|c|c|c|c|c|c|c|c|c|}
\hline Sample $n^{\circ}$ & $\begin{array}{l}\text { Pulling } \\
\text { speed } \\
\left(\mathrm{mm} \cdot \mathrm{h}^{-1}\right)\end{array}$ & Average composition & $\varepsilon_{33}^{\mathrm{T}} / \varepsilon_{0}$ & $\mathrm{k}_{\mathrm{t}}(\%)$ & $\mathrm{k}_{31}(\%)$ & $\mathrm{k}_{32}(\%)$ & $\begin{array}{c}d_{33} \\
\left(p C \cdot N^{-1}\right)\end{array}$ & $\begin{array}{c}\mathrm{T}_{\mathrm{c}} \\
\left({ }^{\circ} \mathrm{C}\right)\end{array}$ & Reference \\
\hline 1 & 15 & $\left(\mathrm{Ba}_{0.889} \mathrm{Ca}_{0.111}\right)\left(\mathrm{Ti}_{0.995} \mathrm{Zr}_{0.005}\right) \mathrm{O}_{3}$ & 755 & 41.0 & 15.5 & 22.2 & 172 & 113 & This work \\
\hline 2 & 15 & $\left(\mathrm{Ba}_{0.885} \mathrm{Ca}_{0.115}\right)\left(\mathrm{Ti}_{0.995} \mathrm{Zr}_{0.005}\right) \mathrm{O}_{3}$ & 670 & 36.1 & 16.8 & 14.4 & 242 & 105 & This work \\
\hline 3 & 9 & $\left(\mathrm{Ba}_{0.882} \mathrm{Ca}_{0.118}\right)\left(\mathrm{Ti}_{0.996} \mathrm{Zr}_{0.004}\right) \mathrm{O}_{3}$ & 1160 & 39.3 & 16.4 & 16.1 & 123 & 112 & This work \\
\hline 4 & 6 & $\left(\mathrm{Ba}_{0.899} \mathrm{Ca}_{0.101}\right)\left(\mathrm{Ti}_{0.979} \mathrm{Zr}_{0.021}\right) \mathrm{O}_{3}$ & 770 & 36.6 & 16.7 & 16.0 & 152 & 107 & This work \\
\hline 5 & 6 & $\left(\mathrm{Ba}_{0.896} \mathrm{Ca}_{0.104}\right)\left(\mathrm{Ti}_{0.993} \mathrm{Zr}_{0.007}\right) \mathrm{O}_{3}$ & 605 & 35.8 & 14.8 & 17.4 & 186 & 107 & This work \\
\hline $\begin{array}{l}(001)_{\mathrm{pc}^{-}} \\
\text {oriented }\end{array}$ & - & $\left(\mathrm{Ba}_{0.798} \mathrm{Ca}_{0.202}\right)\left(\mathrm{Ti}_{0.994} \mathrm{Zr}_{0.006}\right) \mathrm{O}_{3}$ & - & - & - & - & 232 & 125 & 18 \\
\hline
\end{tabular}


$(001)_{\mathrm{pc}^{-}}$

oriented

$\left(\mathrm{Ba}_{0.9819} \mathrm{Ca}_{0.0181}\right)\left(\mathrm{Ti}_{0.9996} \mathrm{Zr}_{0.0004}\right) \mathrm{O}_{3}$

200

120

single crystal

Table 1 : Chemical and electromechanical properties of BCTZ samples grown by $\mu P D$ compared to $(001)_{p c}$-oriented BCTZ single crystals with close compositions

Dielectric and piezoelectric results are in good agreement with literature regarding $(001)_{\mathrm{pc}}$-oriented low-Zr content BCTZ single crystals ${ }^{17,18}$. The polycristalline samples of the present works exhibit similar or slightly higher $\mathrm{d}_{33}$ coefficient whatever the compositions and pulling speeds considered. However, we noted that $\mathrm{k}_{31}$ and $\mathrm{k}_{32}$, which should be strictly equal for isotropic ceramics, display slightly different values. That emphasizes the texture of polycrystals, which display preferential grains orientation as revealed by Laue experiments. The higher dielectric constant $\varepsilon_{33}{ }^{\mathrm{T}} / \varepsilon_{0}$ was obtained for the sample $n^{\circ} 3$ corresponding to the beginning of the second fibre where drop melt occurred (see 4.1). Laue analysis have shown that this sample is strongly polycrystalline and features average isotropic value of the dielectric constant as well as very close values of $\mathrm{k}_{31}$ and $\mathrm{k}_{32}$. Other textured samples display, with (110) and (111) rough crystallographic direction, lower dielectric constants. For the five considered samples, electromechanical thickness coupling factor $\left(\mathrm{k}_{\mathrm{t}}\right)$ are between $36 \%$ and $41 \%$ and the variation of the dielectric constant does not impact significantly this property.

Besides, it is well known that piezoelectric response in single crystals is both compositional and domain size dependent. Considering the results of chemical and Laue crystallographic characterization above mentioned, we assumed that the high growth kinetics and thermal gradients in the micro pulling down technique induces a high rate of defects, leading to a high rate of domain walls pining. The generation of smaller domain sizes may be enabled, as already seen by Wada et al. in $\mathrm{BaTiO}_{3}$ grain oriented ceramics $^{65,66}$ and single crystals ${ }^{67-69}$, enhancing thus the piezoelectric response of $\mu$-PD crystals compared to that of steady TSSG-grown single crystals with same composition.

\section{Conclusion}

Centimetre-sized BCTZ solid solution fibres with large millimetre-sized grains were successfully grown by the micro-pulling down technique. This technique enables the achievement of enhanced control of elemental distribution all along the BCTZ fibres for pulling velocities ranging from 6 to 15 $\mathrm{mm} \cdot \mathrm{h}^{-1}$. Ca and $\mathrm{Zr}$ partition coefficients close to one were obtained and have been significantly decreased compared to those obtained for classically TSSG-grown crystals. Chemical characterization performed through EPMA and LIBS measurements highlighted chemical fluctuations within single crystals. (001)-oriented stripes-like zones exhibiting high or low $\mathrm{Zr} / \mathrm{Ca}$ contents alternatively suggest the coexistence of two perovskite solid solutions with close compositions without being detrimental to the single crystal nature of the characterized zones. Dielectric and electromechanical characterization displayed Curie temperatures up to $113^{\circ} \mathrm{C}, \mathrm{d}_{33}$ up to $242 \mathrm{pC} . \mathrm{N}^{-1}$ and the highest $\mathrm{k}_{\mathrm{t}}$ around $41 \%$, which are in good agreement with single crystals with close compositions. These results obtained by the 
micro pulling down technique open the way of growing lead-free solid solutions with improved chemical and domain size control leading to optimal and competitive piezoelectric performances.

\section{Conflicts of interest}

There are no conflicts to declare

\section{Acknowledgment}

The authors acknowledge the Intelum project (Marie Skłodowska-Curie grant agreement $n^{\circ}$ 644260) for financial support of this work. Ruben Vera and Erwann Jeanneau from Diffraction Centre Henri Longchambon of University Claude Bernard Lyon 1 are acknowledged for XRD experiments.

\section{References}

1 S. Miyazawa, J. Cryst. Growth, 1982, 60, 331-337.

2 T. R. Shrout and S. J. Zhang, J. Electroceramics, 2007, 19, 111-124.

3 S. Zhang, R. Xia and T. R. Shrout, J. Electroceramics, 2007, 19, 251-257.

4 J. Rödel, W. Jo, K. T. P. Seifert, E. M. Anton, T. Granzow and D. Damjanovic, J. Am. Ceram. Soc., 2009, 92, 1153-1177.

5 M. Prakasam, P. Veber, O. Viraphong, L. Etienne, M. Lahaye, S. Pechev, E. Lebraud, K. Shimamura and M. Maglione, Comptes Rendus Phys., 2013, 14, 133-140.

6 D. S. Keeble, F. Benabdallah, P. A. Thomas, M. Maglione and J. Kreisel, Appl. Phys. Lett., 2013, 102, 092903.

7 M. Acosta, N. Novak, V. Rojas, S. Patel, R. Vaish, J. Koruza, G. A. Rossetti and J. Rödel, Appl. Phys. Rev., 2017, 4, 041305.

8 Y. Saito, H. Takao, T. Tani, T. Nonoyama, K. Takatori, T. Homma, T. Nagaya and M. Nakamura, Nature, 2004, 432, 84-87.

9 H. Liu, J. Koruza, P. Veber, D. Rytz, M. Maglione and J. Rödel, Appl. Phys. Lett., 2016, 109, 152902.

10 H. Liu, P. Veber, J. Rödel, D. Rytz, P. B. Fabritchnyi, M. I. Afanasov, E. A. Patterson, T. Frömling, M. Maglione and J. Koruza, Acta Mater., 2018, 148, 499-507.

11 W. Liu and X. Ren, Phys. Rev. Lett., 2009, 103, 257602.

12 Y. Nahas, A. Akbarzadeh, S. Prokhorenko, S. Prosandeev, R. Walter, I. Kornev, J. Íñiguez and L. Bellaiche, Nat. Commun., 2017, 8, 1. 
13 F. Benabdallah, P. Veber, M. Prakasam, O. Viraphong, K. Shimamura and M. Maglione, J. Appl. Phys., 2014, 115, 144102.

14 P. Veber, F. Benabdallah, H. Liu, G. Buse, M. Josse and M. Maglione, Materials (Basel)., 2015, 8, 7962-7978.

15 G. Buse, C. Xin, P. Marchet, A. Borta-Boyon, M. Pham-Thi, H. Cabane, E. Veron, M. Josse, M. Velazquez, M. Lahaye, E. Lebraud, M. Maglione and P. Veber, Cryst. Growth Des., 2018, 18, 5874-5884.

16 Y. Zeng, Y. Zheng, X. Tu, Z. Lu and E. Shi, J. Cryst. Growth, 2012, 343, 17-20.

17 Y. Sun, D. Liu, Q. Li, J. Shim, W. He, H. Fang and Q. Yan, ACS Appl. Mater. Interfaces, 2018, 10, 12847-12853.

D. Liu, J. Shim, Y. Sun, Q. Li and Q. Yan, AIP Adv., 2017, 7, 095311.

J. A. Burton, R. C. Prim and W. P. Slichter, J. Chem. Phys., 1953, 21, 1987.

20 T. Fukuda and H. Hirano, J. Cryst. Growth, 1976, 35, 127-132.

21 S. Matsumura and T. Fukuda, J. Cryst. Growth, 1976, 34, 350-352.

22 C. Fabre, D. Devismes, S. Moncayo, F. Pelascini, F. Trichard, A. Lecomte, B. Bousquet, J. Cauzid and V. Motto-Ros, J. Anal. At. Spectrom, 2018, 33, 1345-1353.

23 L. Sancey, V. Motto-Ros, B. Busser, S. Kotb, J. M. Benoit, A. Piednoir, F. Lux, O. Tillement, G. Panczer and J. Yu, Sci. Rep., 2014, 4, 6065.

24 J. O. Cáceres, F. Pelascini, S. Moncayo, F. Trichard, G. Panczer, A. Marín-Roldán, J.

A. Cruz, I. Coronado and J. Martín-Chivelet, Sci. Rep., 2017, 7, 5080-5090.

25 R. Krimholtz, D. A. Leedom and G. L. Matthaei, Electron. Lett., 1970, 6, 398-399.

26 S. J. H. van Kervel and J. M. Thijssen, Ultrasonics, 1983, 21, 134-140.

27 ANSI/IEEE Std 176-1987, 1988.

28 O. Madelung, U. Rössler and M. Schulz, Eds., in Ternary Compounds, Organic Semiconductors, Springer Berlin Heidelberg, Berlin, Heidelberg, 2000, pp. 1-6.

29 B. Ouladdiaf, J. Archer, G. J. McIntyre, A. W. Hewat, D. Brau and S. York, Phys. B Condens. Matter, 2006, 385-386, 1052-1054.

30 G. Godefroy, P. Lompré, C. Dumas and H. Arend, Mater. Res. Bull., 1977, 12, $165-$ 169.

31 D. Rytz, B. A. Wechsler, C. C. Nelson and K. W. Kirby, J. Cryst. Growth, 1990, 99, $864-868$.

32 K. Lebbou and G. Boulon, in Fiber crystal growth from the melt, eds. T. Fukuda, P. Rudolph and S. Uda, Springer, Berlin, Heidelberg, 2004, pp. 219-254.

33 T. Fukuda and V. I. Chani, in Shaped Crystals, eds. T. Fukuda and V. I. Chani, 
Springer Berlin Heidelberg, 2007.

34 T. Duffar, Ed., Crystal Growth Processes Based on Capillarity: Czochralski, Floating Zone, Shaping and Crucible Techniques, John Wiley \& Sons, Ltd, John Wiley., 2010.

K. Lebbou, Rev. des Tech. l'Ingénieur, 2008, IN 81-1, 1-16.

M. Higuchi, T. Togi and K. Kodaira, J. Cryst. Growth, 1999, 203, 450-453.

M. Guennou, P. Bouvier, B. Krikler, J. Kreisel, R. Haumont and G. Garbarino, Phys. Rev. B - Condens. Matter Mater. Phys., 2010, 82, 1-10.

38 C. Xin, P. Veber, M. Guennou, C. Toulouse, N. Valle, M. Ciomaga Hatnean, G. Balakrishnan, R. Haumont, R. Saint Martin, M. Velazquez, A. Maillard, D. Rytz, M. Josse, M. Maglione and J. Kreisel, CrystEngComm, 2019, 21, 502-512.

D. Sangla, N. Aubry, A. Nehari, A. Brenier, O. Tillement, K. Lebbou, F. Balembois, P. Georges, D. Perrodin, J. Didierjean and J. M. Fourmigue, J. Cryst. Growth, 2009, 312, $125-130$.

40 V. Kononets, E. Auffray, C. Dujardin, S. Gridin, F. Moretti, G. Patton, K. Pauwels, O. Sidletskiy, X. Xu and K. Lebbou, J. Cryst. Growth, 2016, 435, 31-36.

41 X. Xu, K. Lebbou, F. Moretti, K. Pauwels, P. Lecoq, E. Auffray and C. Dujardin, Acta Mater., 2014, 67, 232-238.

42 A. Benaglia, M. Lucchini, K. Pauwels, C. Tully, T. Medvedeva, A. Heering, C.

Dujardin, V. Kononets, K. Lebbou, N. Aubry, S. Faraj, G. Ferro, P. Lecoq and E. Auffray, J. Instrum., 2016, 11, 05004.

43 T. Epicier, G. Boulon, W. Zhao, M. Guzik, B. Jiang, A. Ikesue and L. Esposito, J. Mater. Chem., 2012, 22, 18221.

44 R. C. Devries and R. Roy, J. Am. Soc., 1955, 38, 158-171.

45 B. M. Epelbaum, in Fiber crystal growth from the melt, eds. T. Fukuda, P. Rudolph and S. Uda, Springer Berlin Heidelberg, 2004, pp. 103-127.

46 D. H. Yoon, Opto-Electronics Rev., 2004, 12, 199-212.

47 D. Yoon, J. Cryst. Growth, 1994, 144, 201-206.

48 D. H. Yoon, P. Rudolph and T. Fukuda, J. cr, 1994, 144, 207-212.

49 B. M. Epelbaum, A. Yoshikawa, K. Shimamura, T. Fukuda, K. Suzuki and Y. Waku, J. Cryst. Growth, 1999, 198/199, 471-475.

50 S. Uda, J. Kon, J. Ichikawa and K. Inaba, J. Cryst. Growth, 1997, 179, 567-576.

51 K. A. Jackson, Kinetics processes: Crystal Growth, Diffusion, and Phase Transitions in Materials, WILEY-VCH Verlag GmbH \& Co. KGaA, Weinheim, 2004.

52 C. Kuper, R. Pankrath and H. Hesse, Appl. Phys. A Mater. Sci. Process., 1997, 65, 
$301-305$.

53 L. B. Barbosa, D. R. Ardila and J. P. Andreeta, J. Cryst. Growth, 2001, 231, 488-492.

54 A. Nehari, T. Duffar, E. A. Ghezal and K. Lebbou, Cryst. Growth Des., 2014, 14, 6492-6496.

55 A. Djebli, F. Boudjada, K. Pauwels, V. Kononets, G. Patton, A. Benaglia, M. Lucchini, F. Moretti, O. Sidletskiy, C. Dujardin, P. Lecoq, E. Auffray and K. Lebbou, Opt. Mater. (Amst)., 2017, 65, 66-68.

56 M. Sugiyama, Y. Yokota, Y. Fujimoto, T. Yanagida, Y. Futami, S. Kurosawa and A. Yoshikawa, J. Cryst. Growth, 2012, 352, 110-114.

57 D. Maier, D. Rhede, R. Bertram, D. Klimm and R. Fornari, Opt. Mater. (Amst)., 2007, 30, 11-14.

58 D. Rytz, B. a. Wechsler, C. C. Nelson and K. W. Kirby, J. Cryst. Growth, 1990, 99, $864-868$.

59 D. Damjanovic, Appl. Phys. Lett., 2010, 97, 062906.

60 D. Xue, Y. Zhou, H. Bao, C. Zhou, J. Gao and X. Ren, J. Appl. Phys., 2011, 109, 054110 .

61 H. Bao, C. Zhou, D. Xue, J. Gao and X. Ren, J. Phys. D. Appl. Phys., 2010, 43, 465401.

62 A. Jalalian, A. M. Grishin, X. L. Wang, Z. X. Cheng and S. X. Dou, Appl. Phys. Lett., 2014, 104, 103112.

63 S. Zhukov, Y. A. Genenko, M. Acosta, H. Humburg, W. Jo, J. Rödel and H. von Seggern, Appl. Phys. Lett., 2013, 103, 152904.

64 A. Y. Borisevich, E. A. Eliseev, A. N. Morozovska, C. Cheng, J. Lin, Y. H. Chu, D. Kan, I. Takeuchi, V. Nagarajan and S. V Kalinin, Nat. Commun., 2012, 3, 775-778.

65 S. Wada, K. Takeda, T. Muraishi, H. Kakemoto, T. Tsurumi and T. Kimura, Ferroelectrics, 2008, 373, 11-21.

66 S. Wada, K. Takeda, T. Muraishi, H. Kakemoto, T. Tsurumi and T. Kimura, Jpn. J. Appl. Phys., 2008, 46, 7039.

67 S. Wada and T. Tsurumi, Br. Ceram. Trans., 2004, 103, 93-96.

68 S.-E. Park, S. Wada, L. E. Cross and T. R. Shrout, J. Appl. Phys., 1999, 86, 2746.

69 S. Wada, H. Kakemoto and T. Tsurumi, Mater. Trans., 2004, 45, 178-187. 